\title{
A luta pela terra em território Kaingang: os conflitos na Terra Indígena Xapecó (SC/Brasil) ao longo do século XX
}

Carina Santos de Almeida* Ana Lúcia Vulfe Nötzold ${ }^{* *}$

Resumo: Os Kaingang representam, no Brasil, meridional o maior grupo indígena em população. Sua territorialidade está alicerçada nos múltiplos processos que intervieram nos arranjos espaciais e dinamizaram as relações socioculturais, políticas e econômicas com outros povos indígenas e, sobretudo, com populações não indígenas. A redução da espacialização em território meridional alterou o modus vivendi e o habitus social, consequentemente interferiu na subsistência e autonomia dos Kaingang com o território e o ecossistema. Em 1902, um grupo de Kaingang do sudoeste do Estado do Paraná (Brasil) conquistou uma gleba de terras de aproximadamente 50 mil hectares a partir de um decreto governamental, porém, ao longo do século XX, a Terra Indígena Xapecó, que atualmente pertence

* Doutoranda no Programa de Pós-Graduação em História da Universidade Federal de Santa Catarina/UFSC. Bolsista no Observatório da Educação Escolar Indígena - OEEI/CAPES e pesquisadora junto ao Laboratório de História Indígena/ LABHIN/UFSC. Mestre em Desenvolvimento Regional. E-mail: carina_almaid@ yahoo.com.br. Endereço: Rua Servidão Corintians, n. 54, Ap. 05, Pantanal. CEP 88040-100. Florianópolis, SC.

** Professora no Programa de Pós-Graduação em História da Universidade Federal de Santa Catarina/UFSC. Coordenadora do Observatório da Educação Escolar Indígena - OEEI/CAPES e do Laboratório de História Indígena - LABHIN/ UFSC. Doutora em História. E-mail: anotzold@hotmail.com. Endereço: UFSC Universidade Federal de Santa Catarina, Centro de Filosofia e Ciências Humanas, Departamento de História, LABHIN - Laboratório de História Indígena. Campus Universitário - Trindade. CEP 88040-900. Florianópolis, SC. 
ao Estado de Santa Catarina, foi reduzida a pouco mais de 15 mil hectares. O processo de expropriação da T.I. Xapecó, por não indígenas interessados na usurpação de terra e exploração dos recursos naturais, ocorreu em certa medida com a chancela de funcionários do órgão indigenista do Serviço de Proteção aos Índios e do governo catarinense. Assim, a luta pela terra ao longo do século XX entre atores sociais em condição política e socioeconômica desigual permitiu manter parte do território inicial (30\%) onde vivem atualmente pouco mais de cinco mil indígenas ameríndios.

Palavras-chave: Kaingang. Território. Terra. Conflitos.

\section{Introdução}

Ao longo do século do século XX as terras indígenas Kaingang no sul do Brasil passaram por diversos processos de intervenção tutelar. Estas intervenções promovidas pelos governos estaduais e federal bem como pelos órgãos indigenistas impuseram a fixação de inúmeros grupos indígenas no território pautada nos modelos de desenvolvimento adotados pelo Estado Nacional. Por outro lado, o acesso às terras reservadas, ainda que reduzido se comparado aos tempos pretéritos da história indígena, possibilitou a sobrevivência e, em certa medida, a manutenção da identidade deste povo. Este artigo tece considerações sobre a luta pela terra e os conflitos enfrentados por um grupo de índios Kaingang no decorrer do século XX no oeste catarinense. A Terra Indígena Xapecó se configura como a maior terra indígena de Santa Catarina, seu território que inicialmente ultrapassava 50 mil ha hoje alcança pouco mais de 15 mil ha, os índios Kaingang do Chapecósinho, como comumente são tratados nos documentos do órgão indigenista do Serviço de Proteção aos Índios (SPI), sofreram com a expropriação de posseiros e a grilagem de significativas parcelas de suas terras. Tais indígenas, envolvidos em negociações, acordos, convênios, audiências e interesses escusos foram tratados como tutelados e, dessa forma, tiveram dificuldades em acompanhar os tramites burocráticos acerca da terra.

Sem embargo e em meio aos interesses alheios, os índios do Chapecósinho reagiram aos esbulhos e com o auxílio de não indígenas mantiveram pouco mais de 30\% de seu território inicial. Para compreender esse processo de autonomia Kaingang sobre a Terra

Anos 90, Porto Alegre, v. 18, n. 34, p. 279-303, dez. 2011 
Indígena Xapecó o artigo está estruturado em quatro momentos. Inicialmente apresenta breves considerações acerca do território Kaingang no oeste catarinense, por conseguinte, acusa as transformações que levaram os Kaingang a deixarem de ser tratados pelas políticas indigenistas como bugres e selvagens para serem pensados como camponeses ou agricultores. A seguir, expõe a expropriação de parte da terra e a luta pela mesma nos tramites burocráticos governamentais evidenciando as vicissitudes dos interesses de não indígenas na posse e exploração da terra, e, por fim, encerra com a atuação do indigenismo do SPI e a exploração da Terra Indígena Xapecó pelo órgão tutelar do SPI. O artigo desenvolvido a partir da análise de alguns documentos do SPI coletados no acervo do Museu do Índio no Rio de Janeiro apresenta algumas considerações sobre o processo de autonomia Kaingang, dessa forma, não se esgota em si, visto que existem outros elementos a serem ponderados no contexto da Terra Indígena Xapecó ao longo do século XX.

\section{Considerações acerca do território Kaingang}

Os Kaingang representam, no Brasil meridional, o maior grupo indígena em população, totalizando 33.064 indígenas nos Estados de São Paulo, Paraná, Santa Catarina e Rio Grande do Sul. ${ }^{1}$ Ao longo dos quinhentos anos da terra brasilis, foram nominados em cartas, diários, tratados e crônicas de diversas formas, como Botocudos, Gualachos, Guaianás, Guanhanás, Guñanas, Guayanazes, Chiquis, Pinares, Coroados, Camés, Votorões, entre outros. Em muitos momentos, foram confundidos com outros povos ameríndios, ou mesmo generalizados em um grande grupo "tribal", como é o caso do Tratado descritivo do Brasil, de Gabriel Soares de Sousa, de 1587, publicado no Brasil por Varnhagen, no século XIX. Certa dificuldade de nominação e identificação sociocultural e linguística dos ameríndios brasileiros, sobretudo dos Kaingang, começou a se desfazer quando os estudos etnográficos se tornaram uma prática no Brasil ao fim do século XIX e limiar do século XX.

Os limites étnicos que configuraram a espacialização dos Kaingang foram construídos ao longo dos últimos três mil anos, quando 
os grupos Jê meridionais (Kaingang e Xokleng) ${ }^{2}$ migraram para a região sul do Brasil. Assim, a posse do território e espacialização dos Kaingang dependeu dos contatos, das penetrações, dos conflitos e das guerras travados intragrupal e intergrupal, bem como posteriormente com os luso-brasileiros e imigrantes. Não se sabe ao certo que razões motivaram a migração, porém, esses grupos instalaram-se em territórios de planalto semelhante ao habitat original no planalto central brasileiro e impactaram diminutamente a paisagem do sul do Brasil se comparado aos anos de conquista das fronteiras meridionais por meio das frentes pioneiras (URBAN, 2008).

A Terra Indígena Xapecó está localizada na porção noroeste do Estado de Santa Catarina. Conforme é possível perceber na figura 1, a T.I. Xapecó integra a bacia hidrográfica do rio Chapecó com leito ao noroeste, ao sul, a terra é circundada pela confluência do afluente Chapecozinho, e, ao norte e parte do leste, por limites "secos". Foram nessas terras lindeiras aos atuais limites secos que os Kaingang perderem a posse do território.

A terra possui atualmente pouco mais de 15.623 hectares, porém, este território Kaingang, segundo o Decreto n. ${ }^{\circ}$ 7, de 18 de junho de 1902, assinado pelo então Governador do Estado do Paraná, Francisco Xavier da Silva, garantia uma área reservada a aproximadamente "duzentas almas" da "tribu de índios Coroados" chefiados pelo cacique Vaicrê, de cerca de 50 mil hectares, desde a confluência dos rios Chapecó e Chapecozinho até a estrada de tropas que fazia ligação aos campos sulinos (SANTOS, 1979, p. 22, p. 24-26). Contando com a seguinte ressalva, “[...] fica reservada para o estabelecimento da tribu de indígenas coroados ao mando do cacique Vaicrê, salvo direito de terceiros, uma área de terras [...]" (D’ANGELIS, 2006, p. 316.), foi possível aos posseiros expropriarem parte do território Kaingang com a anuência governamental.

Ao longo do século XX, os Kaingang foram alvos de pressões territoriais e usurpação de suas terras, ficando reduzidos, neste início de século XXI, a pouco mais de 30\% do território que haviam conquistado um século antes. O mapa de localização da Terra Indígena Xapecó, no oeste catarinense, ainda indica duas áreas nominadas de Gleba "A" Pinhalzinho e Gleba "B" Canhadão, que totalizam 660 hectares e foram declaradas, em 19/04/2007, pela Portaria 792, de 20 
de abril de 2007. Segundo o Resumo do Relatório Circunstanciado, Memorial Descritivo e Mapa elaborado pela antropóloga Juracilda Veiga (2003, p. 1), as terras indígenas de Xapecó sofreram “[...] muitas pressões e diversas tentativas de esbulho direto e indireto, com ou sem a participação de autoridades, durante a maior parte do século XX." Tais glebas aguardam homologação do governo federal para que possam ser devidamente (re)apropriadas pelos indígenas da T.I. Xapecó.

\section{Figura 1: Mapa de localização da Terra Indígena Xapecó, no oeste catarinense}

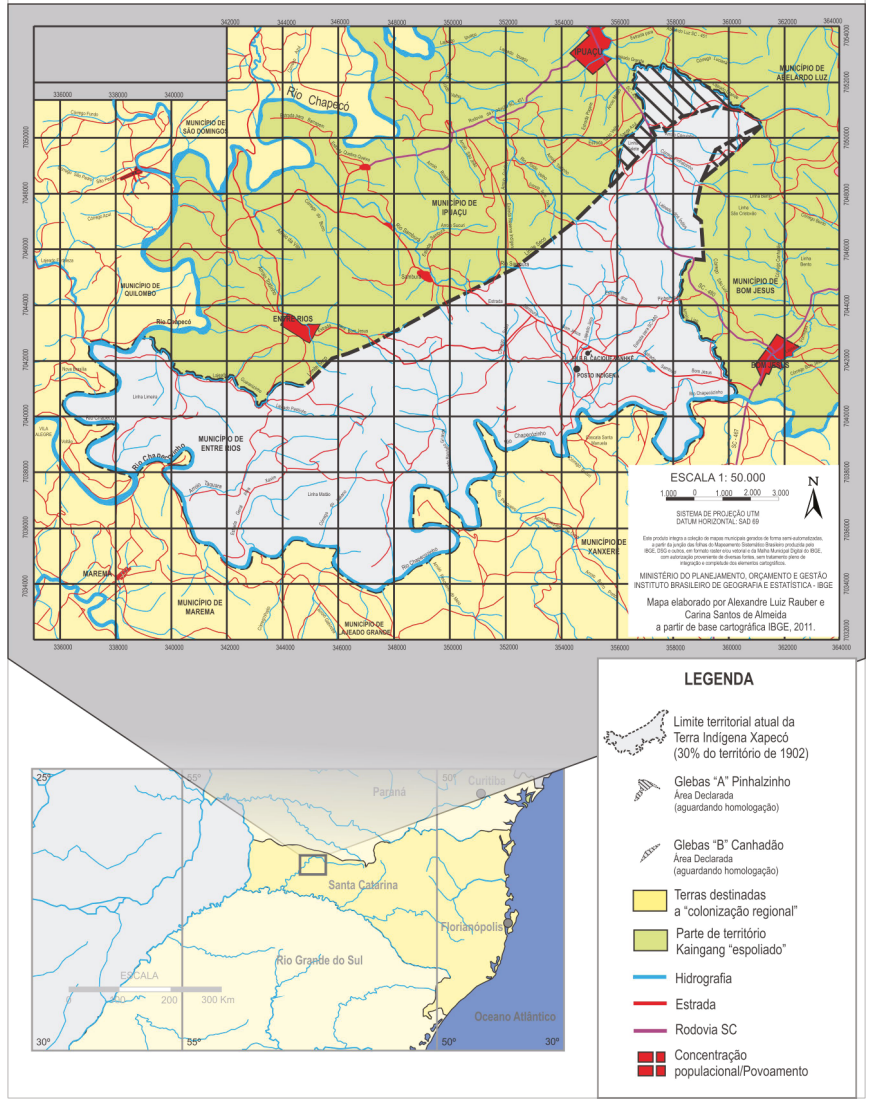

Fonte: Elaborado e adaptado por Carina Santos de Almeida e pelo geógrafo Alexandre Luiz Rauber a partir de base cartográfica IBGE, 2011. 


\section{Os Kaingang: bugres ou camponeses?}

Telemaco Borba, em 1904, após significativa vivência entre os Kaingang do Paraná, ocupando inúmeros cargos oficiais do governo provincial, como administrador de aldeamentos indígenas, afirmava ser o primeiro a denominar estes povos meridionais de "Kaingangues" . ${ }^{3}$ Borba escreveu inúmeras observações sobre os Kaingang do sul do Brasil, e mais especificamente sobre os do Paraná, que em tal período, até a segunda década do século XX, incorporava também os indígenas do oeste catarinense. Contemporâneos a Borba, o frei Luiz de Cimitile e Alfredo D'Escragnolle Taunay também acusam o etnômio Kaingang, ou Kaingangues, Caingangues, Caingangs no último quartel do século XIX. Porém, Lúcio Tadeu Mota (2004) destaca que Franz Keller, engenheiro alemão, responsável por estudar a navegabilidade dos rios Ivaí, Paranapanema, Tibagi e Iguaçu informou em relatório manuscrito de 1867 que os Coroados preferiam se autodenominarem de Caên-gagn. Para Mota, Keller esteve com Telemaco Borba assim como com outros agentes governamentais que administravam aldeamentos indígenas e com populações não indígenas que habitavam o vale do rio Tibagi. Dessa forma, o etnômio Kaingang deveria ser conhecido antes mesmo de 1865 por aqueles que frequentavam estes campos.

O engenheiro belga Pierre F. A. Booth Mabilde (1983), que trabalhou na abertura de estradas nas colônias da região norte da Província do Rio Grande do Sul e que teria sido "prisioneiro" dos Coroados entre 1836 e 1838, não mencionou em seus escritos o termo Kaingang ou palavras de etnômio semelhantes. ${ }^{4}$ Por outro lado, o engenheiro e agrimensor de colônias costumeiramente referia-se aos Coroados como "selvagens" e "bugres". Mabilde afirmava que o termo "bugre" não esclarecia a que "[...] espécie ou raça de indígenas pertence o indivíduo assim chamado [...]” (MABILDE, 1983, p. 7), mas mesmo assim acreditava que "[...] as tribos semelhantes às desta província, encontradas em várias províncias do Império e denominadas de 'bugres', nada mais são do que tribos da Nação Coroados" (Ibid.). Neste sentido, Mabilde destaca que a palavra "bugre" foi difundida e generalizada a partir de um grito agudo de "alerta" que servia de aviso aos companheiros da chegada de pessoa 
estranha nos alojamentos, como "pu-cri-i-i-i-i", entendendo-se como "bugri" ou "bugre". Comumente, a terminologia "bugre" foi empregada para designar o indivíduo herético e posteriormente não catequizado (CATÁLOGO SELETIVO DE DOCUMENTOS REFERENTES AOS INDÍGENAS NO PARANÁ PROVINCIAL 1853-1870, 2007; DE MELO, 2004). De acordo com Bernardino José de Souza (1939, p. 63), o termo bugre foi aplicado indistintamente aos "selvagens do Brasil", ou "[...] aos ameríndios bravos, aos caboclos que ainda erram nas selvas e campos do Brasil interior, qualquer que seja a sua família ou língua."

O termo bugre assumiu e ainda assume vários sentidos, tornando-se polissêmico, sem definição simples, variando de região para região, de um período histórico para outro. Nesse sentido, o termo camponês também caracteriza-se pela sua complexidade de definição. Teodor Shanin (2005, p. 1) compreendia camponês como uma palavra indefinida e mistificada porquanto o conceito estava relacionado com os vínculos de realidade, consistência interna, marco teórico e possíveis esclarecimentos, “[...] 'um camponês', não existe em nenhum sentido imediato e estritamente específico. Em qualquer continente, estado ou região, os assim designados diferem em conteúdo de maneira tão rica quanto o próprio mundo.”. O camponês pode ser tanto o pequeno agricultor, o grande produtor rural, o posseiro, o sem-terra, o proprietário de terras, como o indígena que sobrevive da produção agropecuária. Shanin esclarece que existem categorias que caracterizam e distinguem camponeses dos "outros", como aquele que tem uma ocupação autônoma e que possui o controle dos próprios meios de produção, aquele que apresenta padrões e tendências de organização política, com normas e cognições típicas e semelhantes, com características de organização social e seu funcionamento semelhante em muitas partes do mundo, com uma dinâmica social específica (reprodução social) e com causas e padrões de mudança genéricos e específicos. O camponês tem um "modo de vida", não é uma classe social, mas uma noção.

Os Kaingang da Terra Indígena Xapecó poderiam ser compreendidos como camponeses na medida em que apresentam vínculos estreitos com a terra, subsistindo a partir da agricultura e criação de animais e inseridos em uma região com predominância 
da paisagem rural. O campesinato não indica uma total semelhança dos camponeses, estes distinguem-se de uma sociedade para a outra, inclusive dentro de uma mesma sociedade (SHANIN, 2005, p. 18). Por outro lado, o desenvolvimento agropecuário na T.I. Xapecó não surgiu por meio de uma emergência sociocultural ou econômica (estilo de vida autônomo) endógena. Os Kaingang desta terra, bem como de outras, foram coagidos nos aldeamentos a desenvolverem pecuária e uma agricultura, no mínimo, de subsistência, em consonância com as prerrogativas das políticas indigenistas no Brasil. Da mesma forma que camponês se refere a um "modo de vida", o conceito "indígena" e "índio", também a despeito de milhares de brasileiros terem ascendência indígena, é necessário distinguir o "índio" do "não índio". O índio no Brasil

[...] é todo indivíduo reconhecido como membro por uma comunidade de origem pré-colombiana diversa da nacional e é considerada indígena pela população brasileira com que está em contato (RIBEIRO, 1996, p. 284-285).

O Estatuto do Índio, Lei nº. 6.001, de 19 de dezembro de 1973, inspirado nas discussões de etnologia indígena e, sobretudo, nos estudos de Darcy Ribeiro, definiu em seu artigo $3^{\circ}$ que "I - Índio ou Silvícola -É todo indivíduo de origem e ascendência pré-colombiana que se identifica e é identificado como pertencente a um grupo étnico cujas características culturais o distinguem da sociedade nacional."

Existem diversos modos de vida indígena no Brasil, esta categoria não se resume a uma terminologia estanque; por outro lado, é muito complexa. Assim como o indígena do mundo hodierno não pode ser definido como outrora fora na história do Brasil colonial e imperial - como "gentio" (pagão), "negros da terra" (índios escravizados), "brasis" e "índios" (índios aldeados), categorias empregadas por exploradores, administradores, militares, missionários, viajantes e naturalistas (CUNHA, 1993) - o "camponês" não deve ser laconicamente descrito como um tipo ideal, "anticapitalista", "caipira", "atrasado", "depauperado", visto que o campesinato, com seus processos de ruptura e continuidade ao longo do século $\mathrm{XX}$, possibilitou caracterizar o mundo rural como espaço de vida a 
partir da emergência de "novas ruralidades". Aos indígenas também permite-se pensar como habitantes e trabalhadores do mundo rural (WANDERLEY, 2009).

O que transformou os ameríndios Kaingang de "selvagens" do Brasil ou bugres para camponeses ou agricultores, mas, sobretudo, para índios ou indígenas aldeados e reservados, não foi uma condição endógena ou autônoma para o cultivo da terra, por conseguinte, da lavoura de trigo e soja. Menos ainda eram estes praticantes da pecuária, criação e domesticação de certos animais como o gado, os ovinos e suínos, animais alóctones introduzidos no Brasil. ${ }^{5} \mathrm{O}$ modo de vida e o habitus social Kaingang transformou-se drasticamente ao longo do século XX. Em detrimento dos saberes tradicionais, experiências e práticas socioculturais e econômicas, os Kaingang tornaram-se, obrigatoriamente, homens reservados, aldeados, arrendadores de terras. Fixaram-se no território por meio dos aldeamentos e passaram a ser pensados pelas políticas indigenistas como elemento étnico que deveria ser "civilizado". O principal órgão responsável pela "civilização" e "integração" do índio à sociedade brasileira no século XX foi o SPILTN (Serviço de Proteção ao Índio e Localização de Trabalhadores Nacionais, que, a partir de 1918, passou a se chamar apenas Serviço de Proteção ao Indio, SPI). O SPI foi criado pelo Decreto $n^{\circ}$ 8.072, de 20 de junho de 1910, setor do Ministério da Agricultura, Indústria e Comércio, e tinha por finalidade:

[... a) prestar assistencia aos indios do Brazil, quer vivam aldeiados, reunidos em tribus, em estado nomade ou promiscuamente com civilizados; b) estabelecer em zonas ferteis, dotadas de condições de saiubridade, de mananciaes ou cursos de agua e meios faceis e regulares de communicação, centros agricolas, constituidos por trabalhadores nacionaes que satisfaçam as exigencias do presente regulamento (DECRETO nº 8.072 , de 20 de junho de 1910 , artigo $1^{\circ}$ ).

Não é mera coincidência que o SPI integrasse o Ministério da Agricultura, Indústria e Comércio. Seus objetivos eram introduzir práticas sociais e culturais nacionais, como a instrução escolar e a agricultura e pecuária por meio do fornecimento de 
[...] ferramentas, instrumentos de lavoura, machinas para beneficiar os productos de suas culturas, os animaes domesticos que lhes forem uteis e quaesquer recursos que lhes forem necessarios; introduzir em territorios indigenas a industria pecuaria, quando as condições locaes o permittirem; (DECRETO no ${ }^{\circ} 8.072$, de 20 de junho de 1910, Título I, Capítulo Terceiro, artigo $2^{\circ}$ ).

Por outro lado, o SPI oscilou entre Ministérios, ora integrou o da Agricultura, Indústria e Comércio, de 1910 até 1930, ora o Ministério do Trabalho, de 1930 a 1934, ainda integrou o Ministério da Guerra, por meio da Inspetoria Especial de Fronteiras, de 1934 até 1939, e, em 1936, ao Estado Maior do Exército. Em 1940 retornou ao Ministério da Agricultura, passando a contar com a ajuda do órgão assessor e normativo Conselho Nacional de Proteção aos Índios (CNPI) criado pelo Decreto n ${ }^{\circ} .1 .794$, de 22 de novembro de 1939. Certa condição e inconstância indica, no mínimo, a dificuldade de situar os "silvícolas" no contexto da sociedade brasileira, por vezes, inclinando-os ao campesinato, noutro momento pensados como trabalhadores inseridos numa cadeia produtiva do comércio e indústria por meio da extração de recursos naturais (madeireira, serraria, ervamate, entre outros), e, por fim, como "agentes sociais" estratégicos na "garantia" do território ao governo brasileiro. A Terra Indígena Xapecó manteve-se de 1902 até 1916 sob jurisdição do Estado do Paraná, após o acordo de limites entre Paraná e Santa Catarina (Contestado), passou à jurisdição deste último até 1940, quando então foi instalado um Posto Indígena sob a coordenação do SPI, órgão que se tornou o principal responsável pela T.I.X., até 1967.

\section{Expropriação e luta pela terra}

No oeste catarinense, muitos "colonos" de origem europeia foram inseridos por empresas colonizadoras na primeira metade do século XX. Tais colonizadoras promoveram tanto a comercialização de lotes de terras como a extração da cobertura florestal (WERLANG, 2006, p. 14). Enquanto a pequena propriedade familiar 
se estabelecia no oeste em meio aos campos e "terras devolutas" ocupadas por posseiros e por estancieiros, delegando à região uma nova dinâmica de desenvolvimento, a mata de araucária (pinhais) e faxinais com campos intermitentes possibilitava uma fonte de recursos naturais (energética e de biomassa) expressiva. Ao promover o loteamento de terras, as colonizadoras extraíam da cobertura florestal madeiras de lei, sobretudo a conhecida Araucaria angustifólia, assim, lucravam duplamente, tanto com a comercialização da terra quanto com a da madeira.

A Terra Indígena Xapecó representava um entrave regional ao modelo de desenvolvimento do período. Com significativa vegetação nativa se comparada ao propulsor desmatamento circundante que limpava terrenos para a "colonização", sem o título competente de posse da terra e devido controle efetivo do território pelos Kaingang, na década de 1920 emergiu uma das primeiras tentativas de esbulho "legal" de terras indígenas no "Chapecosinho". ${ }^{6}$ De acordo com um documento de 31 de dezembro de $1923^{7}$, o inspetor da $7^{a}$ Inspetoria Regional do SPI de Curitiba descreve a denúncia efetuada pelo "capitão cacique Kaingang" Crispim Chaves e pelo "cacique" João Alípio a respeito da ação de posse de Eleutério Lemos - que, além de realizar plantações, extração de erva-mate e construção de casa neste terreno, intitulava-se proprietário da "fazenda Chapecosinho" ao lado de José da Silva Carvalho, procurador dos herdeiros de José Joaquim Gonçalves, que outrora também se intitulou proprietário daquelas terras. Os herdeiros deste último alegavam que eram os donos das terras do Chepecosinho por conta de uma hipoteca de 1859, quando Francisco Manoel de Moraes deu como garantia parte das terras de matas e faxinais pelo empréstimo de 200 mil réis que deveriam ser pagos em "um mês". Contudo, tal hipoteca nunca foi executada e nenhuma titulação comprovava que tais terras pertenciam aos autores do litígio.

Por outro lado, o impasse evidenciou-se quando João Roberto Plens "invadiu" as terras de tais "titulares" por conta de arrendamento realizado a partir de um contrato feito com três indígenas do Chapecosinho para "fazer roça", criar animais, desmatar e extrair madeiras e erva-mate. Os autores da ação de medição e posse por meio do Comissário de Terras e com o respaldo do Delegado de 
Polícia de Xanxerê buscavam "expulsar" de tais terras tanto o arrendatário José Roberto Plens quanto os indígenas do Chapecosinho. Neste contexto, surgiu outro representante dos herdeiros e dono de madeireira no Rio Grande do Sul, Alberto Berthier de Almeida, reivindicando tais terras. Os Kaingang conseguiram expulsar o delegado e o comissário de terras, contudo Berthier de Almeida, com a alegação de possuir uma gleba de terras (dentro da T.I. Xapecó, adquirida pela compra) manteve-se até meados do século XX reivindicando, por meio do governo estadual e com a conivência do SPI, a possessão das terras do Chapecozinho (SANTOS, 1979, p. 27-29).

Antonio Selistre de Campos - juiz que assumiu a Comarca de Passo dos Índios em 1931, atual município de Chapecó, e faleceu em 1957 - atuou na defesa dos indígenas do Chapecosinho por meio de denúncias na imprensa local sobre os esbulhos e expropriações que sofriam por parte de posseiros. Para o juiz, o desfecho de 1923 que proporcionou a medição das terras com a chancela do Governador do Estado de Santa Catarina, Adolfo Konder, em $1^{\circ}$ de dezembro de 1927, apesar de não ter originado título de propriedade para os autores da ação, também não significou o desinteresse e a desistência da possessão do Chapecosinho (CAMPOS, 2004 [1948], p. 61-63). Os interesses sobre as terras indígenas, neste caso de estudo a de Xapecó, ${ }^{8}$ não se resumiam apenas à reivindicação de Eleutério Lemos, dos herdeiros de José Joaquim Gonçalves e de Berthier de Almeida. As terras Kaingang passaram a ser normatizadas, seja pelo SPI por meio do desenvolvimento da agricultura (plantio de trigo, feijão, milho e outras lavouras) e da pecuária (bovinos, equinos, muares e suínos), como também exploradas economicamente pelo intrusamento de não indígenas que buscavam arrendar lotes de terra e/ou extrair erva-mate e madeiras de lei por meio de contratos com os Kaingang e com a chancela dos chefes do Posto.

De acordo com o documento de 18 de dezembro de 1933, redigido pelo escriturário Guimorvan de Araújo Winckler, fez-se uma audiência pública e preparatória para a demarcação das terras reservadas pelo Decreto Estadual n ${ }^{\circ}$, de 18 de junho de 1902, do Estado do Paraná, por intermediação do engenheiro Luiz Paulo Dinis Carneiro, representante da capital da República. ${ }^{9}$ Nesta audiência, encontravam-se as partes interessadas nas terras do Chapecosinho, 
o Sr. Alberto Berthier de Almeida, o Sr. Epaminondas Ribas, o Sr. Antonio Rebolho procurador do Sr. Fidêncio de Souza Melo Filho, o Sr. "Major" dos índios Francisco Patrício, o Sr. "Capitão" dos índios Domingo Jacinto, o Sr. "Tenente" dos índios do Toldo Jacu Pedro Inácio e o Sr. "Tenente" dos índios do Toldo Banhado Grande Alfredo Fernandes. ${ }^{10}$ Segundo um documento escrito pelo juiz Antonio Selistre de Campos - num "modesto trabalho de recapitulação histórica" sobre a espoliação a que estavam sofrendo os indígenas do Chapecosinho -, nessa audiência, apesar de os indígenas envolvidos terem aceitado que as partes interessadas requeressem a titulação de terras no Chapecósinho, tal acordo não foi aceito pela maioria dos índios aldeados, tendo dois índios, João Albino e Pedro Luiz, procurado o juiz de Direito da Comarca de Xanxerê para questionar se deveriam retirar-se ou tinham direito a permanecerem em suas terras. Tal juiz confirmou-lhes que somente sairiam se assim desejassem, neste sentido, os dois representantes dos índios do Chapecosinho retornaram aos seus Toldos Jacu e Banhado Grande, reuniram todos os índios aldeados de todos os Toldos e depuseram as autoridades ameríndias que haviam concordado com tal resolução em audiência. ${ }^{11}$

Com a audiência realizada, o Ministério do Trabalho mandou seguir com a medição das terras, assim, o dito engenheiro enviou o mapa e o memorial, mas o SPI, subordinado a este ministério, não aceitou e contestou essa medição, permanecendo o caso sem solução. Assim, segundo Selistre de Campos, continuaram ocorrendo vários "incidentes" entre índios e não índios, mas os Kaingang permaneciam residindo no Chapecosinho. Em 1948, por conta da valorização das terras e ressurgimento de interesse pelas partes no litígio, um funcionário do SPI chamado Cildo Meireles veio ao Chapecosinho estudar o "caso Berthier versus índios do Chapecósinho", e, juntamente com um consultor jurídico do Estado de Santa Catarina, acordaram um "convênio". Esse convênio ratificava a audiência de 1933 que garantia a posse de terceiros dentro da terra Kaingang. Tal convênio contou com a ajuda do agente encarregado do SPI no Posto Indígena Xapecó, Wismar Costa Lima, que justificou sua ação com a seguinte narrativa: 
[...] tenho procurado unicamente morigerar os hábitos perniciosos de nossos índios naquela região, onde campeia os maus vícios do célebre "Contestado", e onde a melhor virtude é saber manejar um revolver. Enquanto permanecer neste Posto, embora com o risco da própria vida e de meus filhos, haverei, dignamente, de seguir o nóbre lema do S.P.I. e fazer do índio um elemento produtivo à si e a própria pátria. ${ }^{12}$

Para contestar este "convênio fantasma", ${ }^{13}$ alguns indigenistas locais solicitaram, dentre eles o juiz Selistre de Campos, ajuda do vice-presidente da República, Nereu Ramos, da Assembleia Legislativa de Santa Catarina e da Câmara dos Vereadores de Chapecó, que intervieram junto ao General Cândido Rondon, então presidente do Conselho dos Índios, bem como ao então diretor do SPI Modesto Donatini Dias Cruz, e ao deputado estadual Cid Loures Ribas. ${ }^{14}$

De acordo com Selistre de Campos, coube ao inspetor substituto da $7^{a}$ Inspetoria Regional do SPI, Deocleciano de Sousa Nenê, no decorrer da década de 1950, resolver o impasse entre Berthier e os Kaingang do Xapecó. Assim, Nenê, como era conhecido o diretor da IR7, procurou "abrir mão de uma parte das terras reservadas aos Índios, em favor do Estado de Santa Catarina, para que seja expedido um Título de Propriedade a favor dos Índios, por intermédio do S.P.I.", conforme narrou Selistre de Campos. ${ }^{15}$ Desde a fundação do jornal $A$ voz de Chapecó em 1939, na qual participou até seu falecimento, em 1957, o juiz Selistre de Campos sempre denunciou em jornais e procurou intervir na defesa dos que ele chamava de "humildes silvícolas" (CAMPOS, 2004 [1949], p. 78 e 88).

Em uma carta enviada ao Governador do Estado de Santa Catarina, Irineu Bornhausen, datada de 15 de janeiro de 1953, bem como em outra enviada ao Presidente da República, Juscelino Kubitschek de Oliveira, de 30 de janeiro de 1957, o juiz Selistre de Campos narrou a espoliação que os índios Kaingang estavam sofrendo, o processo de litígio e o interesse que as terras indígenas despertavam nos posseiros. Ainda que sua morte tenha ocorrido em 1957 e o retorno de suas cartas não tenha chegado, a luta pela terra Kaingang do Chapecosinho permaneceu. 


\title{
O indigenismo do SPI e a exploração da Terra Indígena Xapecó
}

O Posto Indígena Xapecó instalado em 1941, sob a tutela e pressupostos do SPI, buscava a suficiência econômica por meio da "emancipação e incorporação à sociedade brasileira". Para o SPI, a "função educacional e orientadora dos índios" não se baseava apenas em "[...] amar a bandeira e a cantar o hino [...]" mas em ensinar trabalhos e ofícios "civilizados", bem como ajudar "[...] no estabelecimento economico ligado a terra $[. .$.$] ". { }^{16}$ De acordo com o Decreto n¹0.652, de 16 de outubro de 1942, os fins do Serviço eram:

\begin{abstract}
Promover em colaboração com os órgãos proprios, a exploração das riquezas naturais, das industrias extrativas e quaisquer outras fontes de rendimento, relacionadas com o patrimônio indígena, ou dela proveniente, no sentido de assegurar, quando oportuno, a emancipação econômica das tribus. ${ }^{17}$
\end{abstract}

O chefe do posto indígena do SPI tinha como função, em todos os postos, manter os índios aldeados por meio de normatização e "proteção" e ainda ser responsável pela organização e promoção do trabalho agrícola e pecuário. Os postos indígenas no Brasil deveriam alcançar a autossubsistência, o que significava, além da produção de alimentos para o consumo dos aldeados, ainda o cultivo de roçados para o Posto e a comercialização regional. Neste contexto, aos poucos, parte das terras dos indígenas passou a ser arrendada para "colonos" não indígenas ou ainda para posseiros que circundavam as terras do Chapecosinho.

A atuação do SPI nas terras do Chapecosinho estendeu-se de 1941 a 1967, quando a Funai, com ares de renovação dos princípios indigenistas, assumiu a coordenação das políticas públicas aos índios e substituiu o SPI em decorrência de denúncias nacionais de irregularidades. A exemplo dos outros postos indígenas do sul do Brasil, o SPI na Terra Indígena Xapecó fundamentou suas políticas a partir da autossubsistência - sobretudo por não ter recursos orçamentários para a promoção das terras indígenas - a partir da 
agricultura (plantação de trigo, milho, alfafa, feijão e, sobretudo, soja) e arrendamento de terras a terceiros, da pecuária (criação de bovinos, mas também de suínos e ovinos) e da extração e comercialização dos recursos naturais (erva-mate, pinheiros e outras madeiras de lei). Estes foram os pilares da atuação indigenista do SPI na região sul, solidificados pela Funai e presentes até hoje na Terra Indígena Xapecó - com exceção da extração e comercialização de recursos naturais nativos que parcialmente se extinguiram e se encontram em fase de regeneração.

Apesar da década de 1940 ter inaugurado uma nova fase de tutela na Terra Indígena Xapecó, esta veio a imprimir novas formas de exploração tanto dos indígenas quanto de suas terras. A "aculturação" e "assimilação" dos Kaingang da T. I. Xapecó, em meados do século XX, adquiriu outras performances. Se até o início deste século os indígenas foram impelidos a "constituírem uma vida" em aldeamentos de forma "civilizada" e a possibilitarem a ocupação das terras circundantes para a "colonização", foi por meio de práticas agrícolas e da criação de animais que estes ameríndios se inseriram, aos poucos, no processo capitalista de produção agropecuária nacional (agronegócio).

A questão da "aculturação" e "assimilação" indígena - temática que preocupou muitos estudiosos de história e etnologia indígena - tornou-se um grande dilema e objetivo a ser alcançado pelas políticas indigenistas brasileira desde o Marquês de Pombal até a Constituição Federal de 1988. Sobretudo foram as discussões do Instituto Histórico e Geográfico Brasileiro (IHGB) realizadas principalmente por Varnhagen - que acreditava no fenecer das populações indígena - e por Von Martius - que ao contrário do pessimismo de Varnhagen, acreditava que o índio seria capaz de alcançar os degraus da civilização à medida que fosse "assimilado" e "aculturado" pelo branco,$-{ }^{18}$ que conduziram os diferentes povos às novas formas de organização social e cultural (capitalista), bem como estimularam sua "integração nacional". Com o SPI, a "aculturação" e "assimilação" alcançaram seu ápice.

A exploração das terras do Chapecosinho teve, em meados do século XX, seus momentos emblemáticos. A despeito de Alberto Berthier de Almeida - que representou, na década de 1920, interesses 
próprios e de posseiros - ter conseguido a autorização do Governador do Estado de Santa Catarina, em 1927, para a medição das terras solicitadas, este não requereu o título de propriedade. Segundo Selistre de Campos, isso justifica-se porquanto as terras tinham pouco valor comercial e a indústria da madeira estava enfrentando momentos de crise. Já na década de 1940, dez alqueires de terra passaram de Cr\$ 2.000 cruzeiros para Cr\$15.000, bem como um pinheiro, que se adquiria por três ou quatro cruzeiros, passou a valer $\mathrm{Cr} \$ 80$ cruzeiros (CAMPOS, 2004 [1948], p. 61-63).

Segundo os relatórios anuais dos agentes encarregados do Posto Indígena Xapecó, em $1^{\circ}$ de novembro de 1942, a terra possuía 693 índios, e, em 30 de setembro de 1948, o Posto alcançou 905 índios; a grande maioria dos índios pertencia ao povo Kaingang, enquanto um pequeno número ao povo Guarani (residentes no Toldo Lageado Guarani). ${ }^{19}$ Portanto, parece, aos olhos de alguns, que 50 mil hectares de terras significavam muita terra para poucos índios.

$\mathrm{Na}$ década de 1950, o SPI e o Governo de Santa Catarina firmaram acordo para a demarcação da área indígena de Xapecó. Desse acordo, as medições se consolidaram em 1954, aos Kaingang delegaram 15.009,8 hectares, ou seja, 30\% da área inicialmente concedida em 1902. Porém, o processo de titulação foi completado em 1959 e seu devido registro competente em 1965. A certidão foi expedida pelo Registro de Imóveis da Comarca de Xanxerê, em 3 de agosto de 1979. A demarcação administrativa pela Funai somente foi homologada pelo Presidente da República em Decreto n. ${ }^{\circ} 297$ de 29 de outubro de 1991; até então, era composta por duas glebas contínuas, sendo a primeira denominada "Posto Indígena Dr. Selistre de Campos", "adquirida legalmente" em 02 de outubro de 1965 do Instituto de Reforma Agrária do Estado de Santa Catarina/ IRASC, e a segunda gleba, denominada "Pinhalzinho", tendo sido adquirida do "Comércio e Indústria Saulle Pagioncelli". ${ }^{20} \mathrm{O}$ pouco mais de 15 mil hectares permanece em usos e frutos dos Kaingang de Xapecó, porém a população atual da terra alcança mais de cinco mil indígenas vivendo nesse território.

A despeito da titulação e registro das terras Kaingang ter se consolidado - e estes indígenas terem conseguido se manter em parte de seu território conquistado no início do século XX -, outros 
enfrentamentos surgiram. Ainda que os Kaingang cultivassem lavouras, criassem animais e extraíssem erva-mate e madeiras de lei para a autossubsistência de todo o Posto, os relatórios do Posto Indígena Xapecó da década de 1950 e 1960 do SPI descrevem a miséria e as péssimas condições de vida em que viviam. A permanência no território, somada às transformações no modo de vida e no habitus social como a obrigatoriedade da escolarização em língua portuguesa, ${ }^{21}$ a catequização, ${ }^{22}$ as novas formas de alimentação e o contato com doenças, ${ }^{23}$ o trabalho regular e normatizado nas lavouras extensas do Posto $^{24}$ permitiram que a lógica da "sociedade civilizada" transformasse o cotidiano Kaingang. Garantir o território certamente é condição sine qua non para a sobrevivência dos povos indígenas, porém, consentir os "usos e frutos" do espaço aos indígenas brasileiros garantidos pela Constituição Federal de 1988 não significa dar condições sociais e culturais de vida aos povos indígenas no Brasil.

\section{Considerações finais}

A luta pela sobrevivência e autonomia Kaingang na Terra Indígena Xapecó não se encerra nestas brever considerações tecidas aqui. Ademais, sobretudo na segunda metade do século XX, outras demandas emergiram entre os índios Kaingang, bem como outras formas de tutela ganharam envergadura e possibilitaram este grupo se inserir no contexto do desenvolvimento regional. Os índios do Chapecósinho não totalizam hoje apenas "duzentas almas" de indígenas como em 1902, por ora, seu território inversamente não acompanhou o aumento populacional, de $50 \mathrm{mil} \mathrm{ha} \mathrm{passou} \mathrm{a} \mathrm{pouco}$ mais 15 mil ha, este fator por si só confere outros desafios para a sobrevivência e autonomia da comunidade no mundo contemporâneo. Ademais, a atuação do órgão indigenista do SPI não representa um corpo exógeno do processo de desenvolvimento brasileiro, nos meandros das negociações, acordos, convênios, audiências e interesses promovidos pelo órgão tutelar na Terra Indígena Xapecó, como também em outras terras indígenas no Brasil, escondem-se as diretrizes nacionais do (nacional) desenvolvimentismo dos diferentes 
governos, bem como as ideias de aculturação e assimilação e as políticas de integração dos índios à sociedade nacional (regional).

Convém destacar que os Kaingang representam no Brasil o terceiro maior grupo indígena em população e que apesar dos múltiplos processos intervenientes não desapareceram ou foram extintos como alardeavam as vozes pessimistas da intelectualidade e da etnografia do final do século XIX e início do século XX. Os índios Kaingang atualmente letrados em língua portuguesa não são àqueles índios que foram muitas vezes manipulados, explorados e usurpados de suas terras no passado. Após as garantias constitucionais de 1988 não são mais tutelados como crianças e suas terras não são mais administradas pelo órgão indigenista, por outro lado, também não se encaixam no atual modelo de desenvolvimento brasileiro e ainda constituem enquanto população desafio para as políticas públicas indígenas. Estas considerações sobre a luta pela terra em território Kaingang, com ênfase nos conflitos na Terra Indígena Xapecó e ponderadas neste artigo, representam uma faceta das políticas indigenistas e das formas como foram tratados os indígenas ao longo do século XX, muitas outras abordagens e pesquisas situam a complexidade da história indígena no Brasil.

\section{THE STRUGGLE FOR LAND IN KAINGANG TERRITORY: CONFLICT IN THE INDIGENOUS LAND XAPECÓ (SC/BRAZIL) DURING THE TWENTIETH CENTURY}

Abstract: The Kaingang group represent in southern Brazil the largest indigenous population. Its territoriality is rooted in the multiple processes involved in spatial arrangements and relationships and animated the sociocultural, political and economical relations with other indigenous groups and, especially, with nonindigenous populations. The spatial reduction in southern territory changed the modus vivendi and social babitus, and consequently interfered in the subsistence and the autonomy of Kaingang with the territory and the ecosystem. In 1902, a group of Kaingang from the southwest of Paraná (Brazil) conquered a tract of land of approximately 50.000 ha from a government decree, however, throughout the twentieth century The Indigenous Land Xapecó, which currently belongs to the state of Santa Catarina, was reduced to little more than 15.000 ha. The process of expropriation of TI Xapecó by non-indigenous interested in the usurpation of land and natural resources has occurred to some extent with the seal of the employees 
of the Indian Protection Service and the Government of Santa Catarina. Thus, the struggle for land along the twentieth century between social actors in unequal political and socioeconomic condition allowed to keep part of the initial territory $(30 \%)$ where currently live just over five thousand indigenous Amerindians.

Keywords: Kaingang. Territory. Land. Conflicts.

\section{Notas}

${ }^{1}$ FUNASA, 2009; Instituo Socioambiental, ISA, 2011.

${ }^{2}$ A palavra Xokleng não corresponde ao atual etnômio deste povo, que prefere se autodenominar como Laklãnõ, porém, como se trata de uma terminologia muito difundida na documentação, mantem-se tal nominação.

3 "Um exemplo da veracidade da opinião do Snr. Dr. H. von Ihering, sobre a confusão que existe na denominação de tribus, de uma mesma nação, com nomes diferentes é o seguinte: Martius e S.te Hilaire, tratando dos 'Coroados' denominamos de 'Camés'; outros de Bugres, de Corôados ou de Tupys. O primeiro que deu-lhes o verdadeiro e generico nome de Kaingangues penso que fui eu. Os que aldearam no Jatahy chamam-se 'Kaingangue-pê', isto é, Kaingangues legitimos, verdadeiros; mas entre elles distinguem-se em Camés, Cayurucrês e Kaingangues. Os que habitam nas immediações de Guarapuava e Palmas chamam-se Camés. Os da zona comprehendida entre os rios Piquiri e Iguassú, Xocrês, e os da margem direita do Paranapanema 'Nhakfáteitei'. Entretanto, falam todos a mesma lingua, usam as mesmas armas e utensilios e têm os mesmos costumes." (BORBA, 2010 [1904], p. 53 e 54).

${ }^{4}$ De acordo com Wilmar da Rocha D’Angelis (2009 [2006]), Pierre Mabilde não teria sido feito prisioneiro pelos Coroados, como acusam suas biógrafas e bisnetas no livro por elas organizado com os escritos de Mabilde em 1983. Sua principal argumentação pauta-se na justificativa de que, "se" o engenheiro belga tivesse tornado-se prisioneiro, as agências públicas e os jornais da época teriam comentado tal acontecimento e investido na recuperação do raptado, como ocorreu com outros não indígenas e imigrantes que foram prisioneiros dos Kaingang. ${ }^{5}$ Os grupos Jê no Brasil foram pensados inicialmente (década de 1940), sobretudo a partir dos primeiros estudos desenvolvidos por Julian Steward, como "povos marginais", no contexto do determinismo ecológico e evolucionismo; assim, os Kaingang e os Xokleng seriam essencialmente povos "[...] caçadores-coletores de ambientes improdutivos através de uma tecnologia simples [...]”. Esta noção está embasada no conceito de aculturação e, no Brasil, conforme Noelli, Darcy Ribeiro, Betty Meggers e Júlio Melatti, contribuíram para sua difusão. Contudo, 


\section{Carina Santos de Almeida, Ana Lúcia Vulfe Nötzold}

compreender os Jê meridionais como "povos marginais" significa generalizar histórica, social e economicamente tais povos. Nas últimas décadas, as pesquisas sobre povos do tronco linguístico Macro-Jê acusam esses povos de não serem simples caçadores e coletores, e possuírem uma relação com o espaço e seus elementos muito mais complexa (NOELLI, 2004, p. 22).

${ }^{6}$ Chamamos aqui de "legal" por conta de que já havia posseiros que residiam nestas terras em território Kaingang sem a titulação registrada em cartório desde o momento do decreto da terra por parte do governo do Estado do Paraná, em 1902. ${ }^{7}$ Documento de 31 de dezembro de 1923. Planilha 702, Microfilme 064, Fundo SPI. Acervo Museu do Índio, Rio de Janeiro.

${ }^{8}$ Nos documentos do SPI, o Posto Indígena Chapecó era grafado com "ch", mas atualmente é com " $x$ ".

${ }^{9}$ Documento "Audiência Pública" de 18 de dezembro de 1933, Fundo Antonio Selistre de Campos, CEOM, Chapecó.

${ }^{10}$ Ainda hoje na Terra Indígena Xapecó existe, entre os Kaingang, as funções de "Capitão", "Major" e "Tenente". A concessão desses "postos" aos líderes indígenas tornou-se uma prática corrente pelos governos provinciais do Brasil meridional ao longo do século XIX, visto que o "acordo" com "grupos de índios" possibilitava que se consolidassem as frentes de povoamento nos campos e fronteiras ao oeste. A aliança com "grupos indígenas" permitia a instalação de "aldeamentos para a civilização", como também o auxílio bélico em relação aos "grupos selvagens" que confrontavam em território. O ofício do Capitão Comandante do destacamento de Palmas (região na qual as terras dos índios do Xapecó estão inseridas) Hermógenes Carneiro Lobo Ferreira ao Presidente da Província de São Paulo evidencia o descrito: "No dia 20 de Outubro p.p. chegou o índio Vitorino que lhe dei o posto de Capitão em nome do Ilmo Sr. Presidente desta Província, e ele nomeou ao índio Virí Tenente, o Mathias Alferes, e Manoel Sargento de sua companhia, que se compõe de 16 a 20 armas [...] Me dizem os índios querem armas de fogo, e munição, assim como ferramentas para trabalhar." (Palmas, 02 de novembro de 1840, Divisão de Arquivo do Estado de São Paulo. Caixa 230, pacote I, Documento 44, Ordem 1025).

${ }^{11}$ Relato de Selistre de Campos, documento sem data, Fundo Antonio Selistre de Campos, CEOM, Chapecó.

${ }^{12}$ Ofício n. ${ }^{\circ} 24$ enviado por Wismar Costa Lima ao Sr. Lourival da Mota Cabral, em 25/05/1949, Diretor da $7^{a}$ Inspetoria Regional do S.P.I, Curitiba. (Museu do Índio, Microfilme 064, Planilha 703).

${ }^{13}$ Assim denominou este convênio o juiz Selistre de Campos.

${ }^{14}$ Documento "Rápido Escôrço Histórico", de 13 de abril de 1952, Fundo Antonio Selistre de Campos, CEOM, Chapecó. 
${ }^{15}$ Documento "Rápido Escôrço Histórico", de 13 de abril de 1952, Fundo Antonio Selistre de Campos, CEOM, Chapecó.

${ }^{16}$ BOLETIM INTERNO DO SERVIÇO DE PROTEÇÃO AO ÍNDIO. Ministério da Agricultura. Boletim no 10, 30 de setembro de 1942. p. 1. Acervo bibliográfico e documental do Museu do Índio.

${ }^{17}$ BOLETIM INTERNO DO SERVIÇO DE PROTEÇÃO AO ÍNDIO. Ministério da Agricultura. Boletim no30, 31 de maio de 1944. p. 1. Acervo bibliográfico e documental do Museu do Índio.

${ }^{18}$ Von Martius elaborou a tese de uma história ancorada nas especificidades brasileiras, qual seja, a composição de "três raças" que se mesclaram e fundaram o Brasil: branca, negra e índia,

${ }^{19}$ Relatórios do Posto Indígena Xapecó de $1^{\circ}$ de dezembro de 1942 e 30 de setembro de 1948. Planilha 703, Microfilme 064, Fundo SPI. Acervo do Museu do Índio, Rio de Janeiro.

${ }^{20}$ Processo 1240/1989, Fundação Nacional do Índio/Ministério do Interior. Processo acessado na Documentação da Diretoria de Proteção Territorial/Setor Documentação - DPT/ DOC, Fundação Nacional do Índio/FUNAI, Brasília. ${ }^{21}$ A educação e a língua portuguesa foram suportes para atingir a "integração" dos indígenas Kaingang, em 1937 foi fundada a primeira escola na TI Xapecó, Escola Banhado Grande (SALVARO, 2009).

${ }^{22}$ De acordo com Wilmar da Rocha D'Angelis, a "conquista espiritual” dos Kaingang iniciou com uma antiga redução que atendeu aos Gualachos - um grupo Jê da família Kaingang -, Conceição de Nossa Senhora dos Gualachos, na região do alto rio Piquiri e, posteriormente, com outra que atendeu aos Coroados nas margens do rio Tibagi (rios que se localizam no território do Estado do Paraná), denominada de Nossa Senhora da Encarnação, no século XVII. (D’ANGELIS, 2006, p. 269). Por outro lado, com a expulsão da Ordem Jesuíta do Brasil, na segunda metade do século XVIII, a ação missionária dos capuchinhos retomou a propagação da fé católica e catequização a partir do Decreto no 426 (24/07/1845) que estabeleceu o "Regulamento acerca das Missões de Catequese e Civilização dos Índios". No século XX, as relações religiosas complexificam-se, sobretudo com a instalação da Igreja Batista na Terra Indígena Xapecó, no final de 1940 e início de 1950. De acordo com o estudo do antropólogo Ledson K. de Almeida (2004, p. 26-29), neste limiar de século XXI, a Terra Indígena Xapecó conta com a influência e atuação, além da Igreja Católica, das seguintes denominações não católicas: Assembleia de Deus, Assembleia de Deus da Missão, Assembleia de Deus Pentecostal do Brasil, Batista, Cadeia da Prece, Deus é Amor, Quadrangular, Só o Senhor é Deus, Unidade de Jesus e Visão Missionária.

${ }^{23}$ A "comida do branco" ao longo do século XX foi substituindo a "comida antiga", pensada como a "comida forte", assim, a "comida fraca", ou a comida 


\section{Carina Santos de Almeida, Ana Lúcia Vulfe Nötzold}

atual, de influência não indígena, muitas vezes é associada à susceptibilidade às doenças, em virtude de que para a constituição dos corpos, a "comida forte" (comida tradicional Kaingang) possibilitaria fortalecimento à saúde e a adequada fabricação dos corpos (OLIVEIRA, 2009).

${ }^{24}$ Entrevista cedida a Carina Santos de Almeida em 14 de junho de 2011 pelos Kaingang Ernesto Belino e Getúlio Narcizo na Aldeia Sede (Jacu) da Terra Indígena Xapecó.

\section{Referências}

ALMEIDA, Ledson Kurtz de. Análise antropológica das igrejas cristãs entre os Kaingang baseada na etnografia, na cosmologia e dualismo. Tese defendida no Programa de Pós-Graduação em Antropologia Social/PPGAS, Universidade Federal de Santa Catarina/UFSC. Florianópolis, 2004. p. 26-29.

BORBA, Telemaco M. Observações sobre os indigenas do Estado do Paraná. Revista do Museu Paulista, v. VI, p. 53-62. São Paulo: Typographia do Diario Official, 1904. p. 53-54. Disponível em: < http://biblio.etnolinguistica.org/borba_1904_observacoes $>$. Acesso em: 20 de mar. 2011.

CAMPOS, Antonio Selistre de. O Serviço de Proteção aos Índios passa a ser de perseguição aos índios de Chapecósinho. A Voz de Chapecó, ano II, 24 de outubro de 1948. n. 206. Chapecó, Santa Catarina. In: CEOM (Org.). A voz de Chapecó: artigos de Antonio Selistre de Campos - 1939-1957. Chapecó: Argos, 2004, p. 61-63.

. A tragédia do Índio. A Voz de Chapecó, ano VII, 3 de Julho de 1949. n. 242. Chapecó, Santa Catarina. In: CEOM (Org.). A voz de Chapecó: artigos de Antonio Selistre de Campos - 1939-1957. Chapecó: Argos, 2004, p. 78-81.

. Pinhalzinho. A Voz de Chapecó, ano VIII, 2 de Outubro de 1949. n. 255. In: CEOM (Org.). A voz de Chapecó: artigos de Antonio Selistre de Campos - 1939-1957. Chapecó: Argos, 2004, p. 88-90.

CATÁLOGO SELETIVO DE DOCUMENTOS REFERENTES AOS INDÍGENAS NO PARANÁ PROVINCIAL 1853-1870. Curitiba: Imprensa Oficial, 2007.

CUNHA, Manuela Carneiro da. Imagens de indios do Brasil: o século XVI. In: PIZARRO, Ana (Org.). América Latina: palavras, literatura e cultura. São Paulo: Memorial da América Latina; Campinas: Ed. UNICAMP, 1993, p. 151-172. 
D’ANGELIS, Wilmar da Rocha. Para uma história do oeste catarinense. In: Cadernos do CEOM. CEOM 20 anos de memória e história no oeste de Santa Catarina, edição comemorativa, n. 23, 2006, p. 265-343.

. Mabilde e seus "apontamentos" sobre os coroados selvagens: tentando separar informação de mistificação e preconceitos. 25 Reunião Brasileira de Antropologia, Goiânia, 11 a 14 de junho de 2006. Disponível em: <http://docs.google. com/viewer? $\mathrm{a}=\mathrm{v} \& \mathrm{q}=$ cache:_N6_d24I2JwJ:www.ifch.unicamp.br/ihb/Textos / GT48Wilmar.pdf+MABILDE+E+SEUS+\%E2\%80\%9CAPONTAMENTO S $\%$ E2 $\% 80 \% 9 D+S O B R E \& h l=p t-B R \& g l=b r \& p i d=b l \& s r c i d=A D G E E S h p i i R$ 7atFJY5Eaf4kSsEB4jySIXZumI81OBr-bgT7jqVoBBrieCFaqnxS2MgSpi5VWDIxugnSdpihMqeswNG8QpA5Xgz1OIceXHlBvaZTFHNxZd6NNVProfJelhuULNvrQv_o\&sig=AHIEtbTFMyhH9dq1S22YSHj_cwo4k9D6Og>. Acesso em: 30 de jul. 2009.

DE MELO, Osvaldo Ferreira. Glossário de instituições vigentes no Brasil-Colônia e Brasil-Império. Brasília: OAB Editora, 2004.

DECRETO no 8.072, de 20 de Junho de 1910. Disponível em: < http:/ /www2. camara.gov.br/legin/fed/decret/1910-1919/decreto-8072-20-junho-1910504520-republicacao-109749-pe.html>. Acesso em: de jan. 2011.

ESTATUTO DO ÍNDIO. Lei n 6.001, 19 de dezembro de 1973. Disponível em: <http://www.funai.gov.br/quem/legislacao/estatuto_indio.html>. Acesso em jan. de 2011.

MABILDE, Pierre F. A. Booth. Apontamentos sobre os indígenas selvagens da Nação Coroados dos matos da Província do Rio Grande do Sul. São Paulo: IBRASA; Brasília: INL, Fundação Nacional Pró-Memória, 1983.

MOTA, Lúcio Tadeu. A denominação kaingang na literatura antropológica, histórica e lingüística. In: MOTA, Lúcio T.; NOELLI, Francisco S.; TOMMASINO, Kimiye. Novas contribuições dos estudos interdisciplinares dos Kaingang. Londrina: Eduel, 2004, p. 1-16.

NOELLI, Francisco Silva. O mapa arqueológico dos povos Jê no sul do Brasil. In: MOTA, Lúcio T.; NOELLI, Francisco S.; TOMMASINO, Kimiye. Novas contribuições dos estudos interdisciplinares dos Kaingang. Londrina: Eduel, 2004, p. 17-51.

OLIVEIRA, Philippe Hanna de Almeida. Comida forte e comida fraca: alimentação e fabricação dos corpos entre os Kaingáng da Terra Indígena Xapecó (Santa Catarina, Brasil). Dissertação de mestrado defendida no Programa de Pós-Graduação em Antropologia Social/PPGAS, Universidade Federal de Santa Catarina/UFSC. Florianópolis, 2009. 


\section{Carina Santos de Almeida, Ana Lúcia Vulfe Nötzold}

RIBEIRO, Darcy. Os indios e a civilização. A integração das populações indígenas no Brasil moderno. São Paulo: Companhia das Letras, 1996.

SANTOS, Silvio Coelho dos. Indigenismo e expansão capitalista: faces da agonia Kaingang. Trabalho apresentado como requisito ao concurso de professor titular em Antropologia na UFSC, 1979.

SALVARO, Talita Daniel. De geração em geração e o lápis na mão: o processo de revitalização da língua Kaingang na educação escolar indígena/Terra Indígena Xapecó - SC. Dissertação de mestrado defendida no Programa de Pós-Graduação em História/PPGH, da Universidade Federal de Santa Catarina/UFSC. Florianópolis, 2009.

SHANIN, Teodor. A definição de camponês: conceituações e desconceituações - o velho e o novo em uma discussão marxista. Revista Nera, ano 8, n. 7, jul./dez., Presidente Prudente, 2005, p. 1-21.

SOUZA, Bernardino José de. Dicionário da terra e gente do Brasil. Onomástica geral da geografia brasileira. Série $5^{a}$ Brasiliana, v. 16. $4^{a}$ Ed. São Paulo, Rio de Janeiro, Recife/Porto Alegre: Companhia Editora Nacional, 1939.

URBAN, Greg. A história da cultura brasileira segundo as línguas nativas. In: CUNHA, Manuela Carneiro da (Org.). História dos indios no Brasil. 2. ed. São Paulo: Companhia das Letras, 2008. p. 87-102.

VEIGA, Juracilda. Resumo do Relatório de Identificação e delimitação, memorial descritivo e mapa. Encaminhado a AER/FUNAI em 05/09/2003. Sem paginação. Acervo do CEOM.

WANDERLEY, Maria Nazaré Baudel. O mundo rural como um espaço de vida. Reflexões sobre a propriedade da terra, agricultura familiar e ruralidade. Porto Alegre: Editora da UFRGS, 2009.

WERLANG, Alceu Antonio. Disputas e ocupação do espaço no oeste catarinense. A atuação da Companhia Territorial Sul Brasil. Chapecó: Argos, 2006.

Recebido em: 29/10/2011.

Aprovado em: 09/02/2012. 